\title{
Childhood Risk and Protective Factors as Predictors of Adolescent Bullying Roles
}

\author{
Zych, Izabela ; Farrington, David P ; Llorent, Vicente J ; Ribeaud, Denis ; Eisner, Manuel P
}

\begin{abstract}
This study shows longitudinal predictors of involvement in different bullying roles, including mental health, individual, family, peer and school predictors. The analyses were based on a longitudinal prospective study with 916 students followed up from ages 7 to 17 with 7 waves of data. Participants were selected through random sampling and were enrolled in 56 schools. Predictors were measured from ages 7 to 11 and involvement in bullying roles and trajectories from ages 11 to 17 . Predictors of bullying perpetration were gender, substance use, truancy, ADHD, moral neutralization, self-control, parental monitoring, corporal punishment, liking school, and bonding with the teacher and classmates. Predictors of victimization were gender, substance use, truancy, internalizing problems, self-control, ADHD, bonding to classmates, and social activities. Predictors of bully/victims were gender, divorced parents, substance use, internalizing problems, ADHD, sensation seeking, moral neutralization, self-control, corporal punishment, parental monitoring, liking school, bonding to classmates, and social activities. Truancy was a risk factor for perpetration mostly in girls; low self-control was a risk factor for perpetration especially in boys. Truant children with high classmates bonding were at high risk of perpetration. Low parental monitoring was a risk factor for perpetration in children who did not like school. Low social activities with peers were a risk factor for victimization in boys and substance use was a risk factor for victimization especially in children with low self-control. High classmates bonding was protective against victimization in non-truant children and against being a bully/victim in children with high sensation seeking. Early interventions focused on risk and protective factors could possibly protect children from bullying.
\end{abstract}

DOI: https://doi.org/10.1007/s42380-020-00068-1

Posted at the Zurich Open Repository and Archive, University of Zurich

ZORA URL: https://doi.org/10.5167/uzh-197217

Journal Article

Accepted Version

Originally published at:

Zych, Izabela; Farrington, David P; Llorent, Vicente J; Ribeaud, Denis; Eisner, Manuel P (2021). Childhood Risk and Protective Factors as Predictors of Adolescent Bullying Roles. International Journal of Bullying Prevention, 3(2):138-146.

DOI: https://doi.org/10.1007/s42380-020-00068-1 
Cite as: Zych, I., Farrington, D.P., Llorent, V.J., Ribeaud, D. \& Eisner, M.P. (2020). Childhood Risk and Protective Factors as Predictors of Adolescent Bullying Roles. International Journal of Bullying Prevention. Online First https://doi.org/10.1007/s42380-020-00068-1

\title{
Childhood risk and protective factors as predictors of adolescent bullying roles
}

\author{
Izabela Zych, $\mathrm{PhD}^{\mathrm{a}^{*}}$, David P. Farrington, $\mathrm{PhD}^{\mathrm{b}}$, Vicente J. Llorent, $\mathrm{PhD}^{\mathrm{a}}$, Denis \\ Ribeaud, $\mathrm{PhD}^{\mathrm{c}}$ and Manuel P. Eisner, $\mathrm{PhD}^{\mathrm{b}, \mathrm{c}}$ \\ ${ }^{\mathrm{a}}$ Universidad de Córdoba (Spain), ${ }^{\mathrm{b}}$ Cambridge University (UK), ${ }^{\mathrm{c}}$ University of Zurich \\ (Switzerland)
}

Abbreviated title: Childhood predictors of adolescent bullying

Acknowledgements: We thank the Swiss National Science Foundation, the Jacobs Foundation, and the Swiss Federal Office of Public Health for financial support for the zproso study during the period 2009-2015. We are also grateful to the youths, parents and teachers who provided data for the z-proso study.

Correspondence: Izabela Zych, Universidad de Córdoba, Avda. San Alberto Magno S/N, 14004 Cordoba (Spain), izych@uco.es

\begin{abstract}
This study shows longitudinal predictors of involvement in different bullying roles, including mental health, individual, family, peer and school predictors. The analyses were based on a longitudinal prospective study with 916 students followed up from ages 7 to 17 with 7 waves of data. Participants were selected through random sampling and were enrolled in 56 schools. Predictors were measured from ages 7 to 11 and involvement in bullying roles and trajectories from age 11 to 17 . Predictors of bullying perpetration were gender, substance use, truancy, ADHD, moral neutralization, self-control, parental monitoring, corporal punishment, liking school, bondinging with teacher and classmates. Predictors of victimization were gender, substance use, truancy, internalizing problems, self-control, ADHD, bondinging to classmates, and social activities. Predictors of bully/victims were gender, divorced parents, substance use, internalizing problems, ADHD, sensation seeking, moral neutralization, self-control, corporal punishment, parental monitoring, liking school, bondinging to classmates, and social activities. Truancy was a risk factor for perpetration mostly in girls, low self-control was a risk
\end{abstract}


factor for perpetration especially in boys. Truant children with high classmate bondinging were at high risk of perpetration. Low parental monitoring was a risk factor for perpetration in children who did not like school. Low social activities with peers was a risk factor for victimization in boys and substance use was a risk factor for victimization especially in children with low self-control. High classmate bondinging was protective against victimization in non-truant children and against being a bully/victim in children with high sensation seeking. Early interventions focused on risk and protective factors could possibly protect children from bullying.

Keywords: Bullying; longitudinal study; childhood risk and protective factors.

School bullying is a serious public health problem, defined as long-term, frequent and intentionally harmful aggressive behavior among students. In bullying situations, perpetrators inflict harm on victims who find it difficult to defend themselves (Smith \& Brain, 2000). Different bullying roles such as victims, perpetrators and bully/victims have been described. Victimization (being bullied) is related to long-term health issues such as psychosomatic problems (Gini \& Pozzoli, 2013; Gini, Pozzoli, Lenzi, \& Vieno, 2014) and depression later in life (Averdijk, Müller, Eisner, \& Ribeaud, 2011;

Sourander et al., 2016; Ttofi, Farrington, Lösel, \& Loeber, 2011). School bullies have high probability of later offending (Ttofi, Farrington, Losel, \& Loeber, 2011) and drug use (Ttofi, Farrington, Losel, Crago, \& Theodorakis, 2016). Consequences for bully/victims include suicidal thoughts, behavior, and weapon carrying (Zych, OrtegaRuiz, \& Del Rey, 2015). Also, involvement in any bullying role is related to suicidal thoughts and behavior (Holt et al., 2015), weapon carrying (Valdebenito, Ttofi, Eisner, \& Gaffney, 2017), and other adult psychiatric outcomes (Copeland, Wolke, Angold, \& Costello, 2013). Thus, understanding and reducing school bullying is urgently needed, and protecting children against bullying and its consequences is crucial for their health and well-being.

Bullying is an aggressive behavior that can occur in any age group. There are many studies focusing on bullying variations with age, mostly focused on its manifestations and prevalence rates. Nevertheless, to our knowledge, longitudinal studies focused on the age of onset have not been conducted yet. Although it is difficult to compare bullying rates among different age groups, longitudinal studies showed that bullying victimization rates generally decreased with age (Cross, Lester, \& Barnes, 2015; Kim, Boyce, Koh, \& Leventhal, 2009; Schafer, Korn, Brodbeck, Wolke, \& Schulz, 2005; Sourander, Helstela, Helenius, \& Piha, 2000; Swearer \& Cary, 2003). Perpetration seems to be rather constant if different studies are compared, although with inconsistent findings (Kim et al. 2009; Schafer et al., 2005; Sourander et al., 2005; Swearer et al., 2003; Zych, Ttofi, Farrington, Ribeaud, \& Eisner, 2020).

Although the number of studies on bullying has increased greatly throughout the past decades, most of the research on this topic is cross-sectional and correlational (Zych, et al., 2015), and there are only several longitudinal studies about bullying (Zych et al., 
2020). Bullying is often analyzed from an ecological perspective (Espelage, Rao, \& De la Rue, 2013) that focuses on the interaction of a person with their environment, including different individual and social factors, family, peers, and school climate (Espelage, 2014). Thus, bullying is not only an individual behavior, but it is a result of a dynamic interaction among different factors from an ecological perspective. A recent systematic review of meta-analyses showed that individual, peer, family, school and community factors are all related to bullying perpetration, victimization and being a bully/victim (Zych, Farrington, \& Ttofi, 2019), but most of the studies are cross-sectional and do not make it possible to distinguish predictors from correlates. Moreover, studies usually focus on a few risk or protective factors only and therefore, it is not possible to discover which factors are the most important and predict bullying after controlling for covariates.

Regarding individual factors, a systematic review and meta-analysis by Cook, Williams, Guerra, Kim, and Sadek (2010) found that internalizing and externalizing behaviors predicted bullying victimization and perpetration. Another meta-analysis discovered that drug use was related to both bullying victimization and perpetration (Valdebenito, Ttofi, \& Eisner, 2015). Moral disengagement and impaired morality in general were found to be risk factors for bullying perpetration (Gini, Pozzoli, \& Hymel, 2014; Romera, Casas, Gomez-Ortiz, \& Ortega-Ruiz, 2019). Attention deficit and hyperactivity were described as important longitudinal predictors of offending (Young, Moss, Sedgwick, Fridman, \& Hodgkins, 2015), but research on the relation between ADHD and bullying is still in its early stages. A study with Italian adolescents found that ADHD was related to bullying perpetration in boys and victimization in girls (Bacchini, Affuso, \& Trotta, 2008). Unnever and Cornell (2003) studied more than 1,300 US adolescents and found that bullying victimization was related to ADHD, and bullying perpetration was related to low self-control. A study with Greek adolescents found that sensation seeking was related to bullying perpetration (Antoniadou, Kokkinos, \& Markos, 2016).

Parental factors such as high parental involvement and good supervision were found to be related to less victimization and lower rates of being a bully/victim in a metaanalysis conducted by Lereya, Samara, and Wolke (2013). A retrospective study with Japanese, South African and US young people showed that physical child harm was related to bullying victimization, perpetration and being a bully/victim (Dussich \& Maekoya, 2007). Family conflict and divorce are important predictors of antisocial behavior and offending (Farrington, Ttofi, Crago, \& Coid, 2015), but little is known about their relation to bullying.

Also, according to meta-analytic findings, low quality of peer relationships was found to be related to any bullying role (Cook, et al., 2010). According to a systematic review of meta-analyses, prosociality was a protective factor against victimization, and peer status, and support were protective against victimization, perpetration and being a bully/victim (Zych, et al., 2019). Nevertheless, a study with Spanish, Colombian and Irish adolescents reported that victims scored high on prosociality and bullies scored high on 
social efficacy (Gomez-Ortiz, Romera, Ortega-Ruiz, Herrera, \& Norman, 2019). Thus, findings on peer relations and bullying are inconsistent.

Regarding school factors, a systematic review of meta-analyses showed that high academic performance was related to less bullying perpetration and victimization (Zych, et al., 2019) and a study with a nationally representative sample of US adolescents found that bullying victimization was related to truancy (Gastic, 2008). A positive school climate includes different dimensions related to teachers, peers and school in general (Del Rey, Casas, \& Ruiz, 2017). Meta-analytic findings showed that positive school climate was a protective factor against bullying perpetration, victimization and being a bully/victim (Cook, et al., 2010).

Thus, different meta-analyses and cross-sectional studies discovered individual, family, peer, and school factors related to different bullying roles. The ecological approach states that bullying is a result of a dynamic interaction among these factors. Nevertheless, given the cross-sectional designs of these studies, predictors cannot be distinguished from consequences or correlates. On the other hand, there are several prospective longitudinal studies that examined early predictors of bullying. It was found that internalizing and externalizing problems predicted victimization over time (Brendgen, Girard, Vitaro, Dionne, \& Boivin, 2016; Reijntjes et al., 2011; Reijntjes, Kamphuis, Prinzie, \& Telch, 2010). Children who were physically abused by their parents at age 12 tended to be bullied by peers at age 16 (Benedini, Fagan, \& Gibson, 2016). A twin study showed that internalizing and externalizing problems, low family support and high child maltreatment predicted chronic peer victimization across primary and secondary school (Bowes et al., 2013). Impulsivity tended to predict bullying victimization and perpetration one year later (Fanti \& Kimonis, 2013), and low commitment to school was related to bullying perpetration two years later (Hemphill et al., 2012), although this relation was no longer significant after controlling for other variables.

A longitudinal study over seven years showed that adolescent victims tended to be unpopular and disliked in childhood, whereas bullies tended to be rather popular (Pouwels et al., 2017). All these studies shed light on longitudinal predictors of bullying, but most of them include only a few predictors in a few data waves. Nevertheless, violence should be considered from a comprehensive and multifactorial perspective (Eisner \& Malti, 2015). At the same time, it is necessary to study bullying from an ecological perspective (Espelage, 2014). Thus, new studies are needed to discover longterm risk and protective factors and unique relations between these factors and bullying roles. Longitudinal studies including a broad range of childhood risk and protective factors for adolescent bullying can provide a global vision of the problem, making it possible to distinguish predictors from correlates, and consequences. Moreover, to our knowledge, longitudinal predictors taking into account different age of onset of bullying have not been studied yet. 
Thus, the present large-scale study focused on mental health, individual, family, peer and school variables in childhood (ages 7 to 11) and their relation with different bullying roles in adolescence (ages 11 to 17). Unique associations between these predictors and involvement in bullying as victims, perpetrators and bully/victims were tested, focusing on early onset, late onset, and persistent involvement in bullying.

\section{Methods}

\section{Participants}

This study was based on 916 participants at age 7 in 2004 followed up at ages 8, $9,11,13,15$ and 17. It is a part of BLINDED project, a prospective longitudinal cohort study focused on life development (blinded). The initial target sample consisted of 1,675 children who entered the school system in Zurich and whose 56 schools were randomly selected to participate in this study from 90 public schools in Zurich. At age 7, 1,361 participated in the first survey wave. Parental consent was obtained in each stage of the study. At age 11, parental consent had to be renewed, which caused some attrition and reduced the sample to 1,144 children. After eliminating participants with missing data (see data analysis for details), the final sample included 916 children. An analysis of nonresponse and attrition showed that the current data are relatively representative (Eisner, Murray, Eisner, \& Ribeaud, 2019).

Among the participants, $50.0 \%$ were boys, and $89.5 \%$ were born in Switzerland. Participants had diverse religious, ethnic and educational backgrounds, with parents born in 80 different countries including Switzerland (41.2\%), former Yugoslavia (13.4\%), Sri Lanka (5.7\%), Germany (5.3\%), Portugal (4.7\%), and Turkey (4.3\%). Regarding the religious background, 25.2\% identified as Roman Catholics, 24.2\% as Protestants, $16.6 \%$ as Muslims, $7.3 \%$ as Christian Orthodox, $4.9 \%$ as Hindi, $1.4 \%$ of other denominations, and $20.4 \%$ identified no religious denomination.

\section{Measures}

Bullying perpetration and victimization were measured using the Zurich Brief Bullying Scales (Murray et al., 2019) where students were asked if they had been bullied or had bullied others in the past year (e.g., at school, on the way to school, when outside, at home, or on the internet), including 4 items on victimization and 4 items on perpetration (social exclusion, verbal, physical and destroying property) answered on a 6-point Likert scale that ranged from 1 (never) to 6 (almost every day). This questionnaire was answered at ages 11, 13, 15 and 17, and showed good reliability with Cronbach's alphas for victimization ranging from .69 to.77 and for perpetration from .68 to .78 in the current sample.

The Social Behavior Questionnaire (SBQ; Tremblay et al., 1991) was adapted to measure child self-reported non-aggressive externalizing behavior at ages 7, 8 and 9 (9 items on opposition, defiance, stealing, lying, vandalizing), internalizing problems at ages 
7 and 9 (9 items on anxiety and depression), ADHD (8 items) administered at ages 7 and 9 , and prosocial behavior (10 items on helping and empathy) at ages 7, 8, 9 and 11. This instrument was administered using a computer, where children were shown pictures with different behaviors and audio items. The items were answered on a yes/no scale. The questionnaire showed acceptable reliability (Cronbach's alphas ranging from .60 to .75).

Sensation seeking was measured using a cardboard "travel game" at age 7 (Alsaker, Nägele, Valkanover, \& Hauser, 2008). Children were told that they were going on a trip and were asked to move through the board, encountering different risky and nonrisky situations. There were 9 items, and Cronbach's alpha was .68.

Moral neutralization of aggression (frequently labelled as moral disengagement) was measured using the Unified Moral Neutralization (Ribeaud \& Eisner, 2010a) paper survey at age $11(\alpha=.61)$. The scale includes 16 items (e.g., it is fine to be mean if others misbehave, it is fine to fight to protect your rights) answered on a 4-point Likert scale ranging from 1 (fully untrue) to 4 (fully true).

Low self-control was measured with an instrument based on the Grasmick scale (Grasmick, Tittle, Bursik, \& Arneklev, 1993) at age $11(\alpha=.75)$. This included 10 items (e.g., act without thinking, lose control quickly) answered on a 4-point Likert scale ranging from 1 (fully untrue) to 4 (fully true).

Supportive parenting (8 items, e.g., talk, help, play), monitoring (5 items, e.g., parents know where you are) and corporal punishment (3 items, e.g., spank, slap) were based on the Alabama Parenting Questionnaire (Shelton, Frick, \& Wootton, 1996) answered on a 4-point Likert scale ranging from 1 (never) to 4 (always) in a paper survey at age 11. Cronbach's alphas ranged from .54 to .66 .

Truancy (last year) was measured at age 11 with one item (skipped school on purpose) and last year substance use was measured with three items including drinking alcohol, smoking cigarettes and cannabis use. These items were responded on a yes/no scale.

Social activities with peers were measured through an Unstructured Leisure scale administered at age 11. The scale used 8 items about activities with peers (e.g., shop with friends, meet with friends, play outside) answered on a 6-point Likert scale ranging from 1 (never) to 6 (every day). Cronbach's alpha was good $(\alpha=.79)$.

School factors were measured at age 11 by three scales including three items each: liking school (e.g., enjoying going to school; $\alpha=.72$ ), bonding to teacher (e.g., teacher helps me; $\alpha=.78$ ) and bonding to classmates (e.g., getting along with other kids, $\alpha=.77$ ).

In summary, the risk factors were internalizing and externalizing problems, ADHD, sensation seeking, moral neutralization, low self-control, parental corporal punishment, truancy, substance use, and divorced parents. The protective factors were prosocial behavior, supportive parenting, parental monitoring, social activities with peers, liking school, bonding to teacher and bonding to classmates. Although other variables 
were measured in the project, variables that measure the same or a similar construct as the outcome were not included in this article because it focuses on explanatory risk and protective factors (i.e., factors that measure a construct that is clearly different from the outcome). Most of these instruments are widely used in international research and show good psychometric properties (Ribeaud \& Eisner, 2010b).

\section{Data analyses}

To classify participants on different bullying roles, items were dichotomized. As suggested by Solberg and Olweus (2003), students who reported no bullying or bullying only once or twice were considered uninvolved. Students who reported bullying three to 10 times a year or more were classified as involved. Participants with missing data on 2 or more of the 4 items at any wave were eliminated and the remaining participants with missing data $(n=28)$ had data imputed.

Bullying roles were formed through Latent Transition Analysis with SAS 9.4 software Proc LTA macro, following the manual by Collins and Lanza (2010). A combination of different statistics $\left(\mathrm{G}^{2}\right.$, AIC, BIC, log-likelihood) was used to check how many bullying roles were in the data. Participants were grouped in bullying roles based on their probabilities of affirmative answers to items on bullying perpetration and victimization at each wave (ages 11,13,15 and 17) and probabilities of transitions among the bullying roles across these waves were calculated. See BLINDED for more details.

After classifying the participants in the bullying roles through LTA, longitudinal patterns were obtained by recoding different combinations of involvement taking into account all the waves. Participants were considered uninvolved if they were not involved in bullying in any wave. Early onset victims started to be victimized at age 11. Late onset victims started to be victimized from age 13 onwards. Persistent victims were a subset of victims who were victimized in 3 or 4 waves. The same criteria were applied to perpetrators and bully/victims (perpetrators and victims at the same time). These categories were not mutually exclusive in a sense that the same participant could report being in one bullying role at one time point and a different role at other time points.

Given that most of the variables were not linearly related to bullying, risk and protective factors were dichotomized. This was done with a k-means cluster analysis procedure in PAWS Statistics software. This analysis classifies participants into lowscore and high-score groups according to a heuristic algorithm. When a variable was measured only once (e.g., risk-taking measured at age 7), only one variable was clustered into low (0) and high (1). When a variable was measured in several waves (e.g., prosocial behavior was measured at ages 7, 8,9 and 11) all the waves were entered so that participants were classified as low (0) versus high (1) considering all waves.

Logistic regression analyses with a forward stepwise procedure were performed with risk and protective factors at ages 7 to 11 as explanatory variables and bullying roles at ages 11 to 17 as outcome variables. This procedure enters significant predictors and stops when no more significant predictors are found. Given that hypotheses were 
directional, Odds Ratios (OR) with 90\% confidence intervals (CI) were calculated. Listwise deletion of the missing data was used in the logistic regression analyses, with percentages of missing data ranging from $10.9 \%$ to $12.9 \%$. Interactions between significant predictors were tested by entering both predictors and an interaction term. Interactions were tested with two-tailed significance tests and only for predictors with significant main effects.

\section{Results}

Latent Transition Analysis showed that the best fitting model classified participants into four roles: bullies, victims, bully/victims and uninvolved students (two group model log-likelihood $=-9,926.38, \mathrm{G}^{2}=9,602.04, \mathrm{AIC}=9,744.04, \mathrm{BIC}=$ 10,086.26; three-group model: log-likelihood $=-9,664.38, \mathrm{G}^{2}=9,078.04, \mathrm{AIC}=$ 9,310.04, BIC = 9,869.16; four-group model: log-likelihood $=-9447.54 ; \mathrm{G}^{2}=8644.35$; $\mathrm{AIC}=8978.35 ; \mathrm{BIC}=9783.29$ ).

Regarding different roles, $65.7 \%$ of the participants reported being nonperpetrators, $15.5 \%$ were early onset perpetrators, and $18.7 \%$ were late onset perpetrators. Regarding victimization, $66.8 \%$ of the participants reported being non-victims, $13.8 \%$ early onset victims, and $19.4 \%$ late onset victims. Also, $82.7 \%$ of the participants reported not being bully/victims, $10 \%$ were early onset bully/victims, and $7.3 \%$ were late onset bully/victims. Regarding persistence, $25.3 \%$ of the participants reported perpetration at one or two timepoints, and $9 \%$ reported perpetration at three to four timepoints. Victimization at one or two timepoints was reported by $23.3 \%$ of the participants and victimization at three to four timepoints by $9.9 \%$. Being a bully/victim at one to two timepoints was reported by $15.5 \%$ of the participants and being a bully/victim at three or four time points by $1.8 \%$. These categories were not mutually exclusive and, overall, only $34.6 \%$ of the participants reported never having been involved in bullying (any timepoint, any role).

Logistic regression analyses showed that factors such as self-reported externalizing problems, self-reported prosocial behavior, and supportive parenting did not predict any bullying role. Significant predictors for different bullying roles are shown in table 1.

Risk factors for bullying perpetration were male gender (late onset $\mathrm{OR}=3.45$, persistent $\mathrm{OR}=3.10$ ), substance use (early onset $\mathrm{OR}=2.89$, persistent $\mathrm{OR}=3.06$ ), truancy (persistent $\mathrm{OR}=4.71$ ), ADHD (late onset $\mathrm{OR}=1.62$ ), moral neutralization (early onset $\mathrm{OR}=1.70$, late onset $\mathrm{OR}=1.97$, persistent $\mathrm{OR}=1.94$ ), low self-control (early onset $\mathrm{OR}=1.87$, persistent $\mathrm{OR}=2.40$ ), and high corporal punishment (late onset $\mathrm{OR}=2.13$ ). Protective factors against perpetration were good parental monitoring (early onset $\mathrm{OR}=$ .45 , persistent $\mathrm{OR}=.53$ ), liking school (early onset $\mathrm{OR}=0.55$ ), bonding with teacher (late onset $\mathrm{OR}=0.32$ ), and bonding with classmates (early onset $\mathrm{OR}=0.38$ ).

Risk factors for victimization were being a boy (late onset $\mathrm{OR}=1.45$ ), substance use (late onset $\mathrm{OR}=2.46$, persistent $\mathrm{OR}=4.05$ ), truancy (early onset $\mathrm{OR}=3.71$ ), 
internalizing problems (persistent $\mathrm{OR}=1.56$ ), low self-control (early onset $\mathrm{OR}=1.70$, persistent $\mathrm{OR}=1.78$ ), and $\mathrm{ADHD}$ (late onset $\mathrm{OR}=1.71$ ). Bonding to classmates was a protective factor against victimization (early onset $\mathrm{OR}=0.21$, late onset $\mathrm{OR}=0.46$, persistent $\mathrm{OR}=0.31$ ).

Risk factors for bully/victims were male gender (early onset $\mathrm{OR}=10.56$, late onset $\mathrm{OR}=1.80$, persistent all males), divorced parents (late onset $\mathrm{OR}=2.46$ ), substance use (early onset $\mathrm{OR}=3.42$, persistent $\mathrm{OR}=5$ ), internalizing problems (early onset $\mathrm{OR}=$ 2.43), $\mathrm{ADHD}$ (persistent $\mathrm{OR}=4.12$ ), sensation seeking (late onset $\mathrm{OR}=1.95$ ), moral neutralization (early onset $\mathrm{OR}=2.44$ ), low self-control (early onset $\mathrm{OR}=3.14$, persistent $\mathrm{OR}=8.99$ ), corporal punishment (early onset $\mathrm{OR}=4.60$ ). Protective factors against being a bully/victim were parental monitoring (late onset $\mathrm{OR}=0.54$ ), liking school (persistent $\mathrm{OR}=0.10$ ), bonding to classmates (early onset $\mathrm{OR}=0.16$, persistent $\mathrm{OR}=0.15$ ), and social activities with peers (early onset $\mathrm{OR}=0.49$ ).

Table 1. Risk and protective factors for different bullying roles 


\begin{tabular}{|c|c|c|c|c|c|c|c|c|c|c|c|c|}
\hline \multirow[b]{3}{*}{ Gender (boys) } & \multicolumn{3}{|c|}{$\begin{array}{c}\text { Bullies } \\
n=253\end{array}$} & \multicolumn{3}{|c|}{$\begin{array}{l}\text { Early onset bullies } \\
n=115\end{array}$} & \multicolumn{3}{|c|}{$\begin{array}{l}\text { Late onset bullies } \\
n=143\end{array}$} & \multicolumn{3}{|c|}{$\begin{array}{c}\text { Persistent bullies } \\
n=68\end{array}$} \\
\hline & \multirow{2}{*}{$\frac{\mathrm{OR}}{2.43}$} & \multicolumn{2}{|c|}{$90 \% \mathrm{CI}$} & \multirow[t]{2}{*}{ OR } & \multicolumn{2}{|c|}{$90 \% \mathrm{CI}$} & \multirow{2}{*}{$\begin{array}{l}\text { OR } \\
3.45\end{array}$} & \multicolumn{2}{|c|}{$90 \% \mathrm{CI}$} & \multirow{2}{*}{$\begin{array}{ll}\text { OR } \\
3.10\end{array}$} & \multicolumn{2}{|c|}{$90 \% \mathrm{CI}$} \\
\hline & & 1.77 & 3.33 & & ns & & & 2.35 & 5.06 & & 1.83 & 5.23 \\
\hline Substance use & & ns & & 2.89 & 1.32 & 6.32 & & ns & & 3.06 & 1.31 & 7.12 \\
\hline Truancy & 2.31 & 1.01 & 5.31 & & ns & & & ns & & 4.71 & 1.69 & 13.11 \\
\hline ADHD & & ns & & & ns & & 1.62 & 1.07 & 2.44 & & ns & \\
\hline Moral neutralization & 1.68 & 1.15 & 2.43 & 1.70 & 1.07 & 2.71 & 1.97 & 1.30 & 2.98 & 1.94 & 1.10 & 3.42 \\
\hline Low & 1.65 & 1.17 & 2.34 & 1.87 & 1.20 & 2.91 & & $\mathrm{~ns}$ & & 2.40 & 1.37 & 4.21 \\
\hline Parental monitoring & 0.53 & 0.36 & 0.77 & 0.45 & 0.28 & 0.71 & & ns & & 0.53 & 0.30 & 0.93 \\
\hline Corporal punishment & & ns & & & ns & & 2.13 & 1.01 & 4.49 & & ns & \\
\hline Liking school & & ns & & 0.55 & 0.35 & .87 & & ns & & & ns & \\
\hline Teac & 0.50 & 0.29 & 0.86 & & ns & & 0.32 & 0.18 & 0.59 & & ns & \\
\hline Classmates bon & 0.47 & 0.29 & 0.75 & 0.38 & 0.21 & 0.66 & & ns & & & $\mathrm{ns}$ & \\
\hline \multirow[t]{3}{*}{ Nagelkerke $\mathrm{R}^{2}$} & .20 & & & .22 & & & .21 & & & .28 & & \\
\hline & \multicolumn{3}{|c|}{$\begin{array}{c}\text { Victims } \\
n=254\end{array}$} & \multicolumn{3}{|c|}{$\begin{array}{c}\text { Early onset victims } \\
n=102\end{array}$} & \multicolumn{3}{|c|}{$\begin{array}{l}\text { Late onset victims } \\
\quad n=152\end{array}$} & \multicolumn{3}{|c|}{$\begin{array}{c}\text { Persistent victims } \\
n=72\end{array}$} \\
\hline & OR & \multicolumn{2}{|c|}{$90 \% \mathrm{CI}$} & OR & \multicolumn{2}{|c|}{$90 \% \mathrm{CI}$} & OR & \multicolumn{2}{|c|}{$90 \% \mathrm{CI}$} & OR & \multicolumn{2}{|c|}{$90 \% \mathrm{CI}$} \\
\hline Gend & & & & & ns & & 1.45 & 1.02 & 2.06 & & & \\
\hline Substance use & 2.43 & 1.22 & 4.83 & & ns & & 2.46 & 1.17 & 5.14 & 4.05 & 1.67 & 9.79 \\
\hline Truancy & & ns & & 3.71 & 1.44 & 9.55 & & ns & & & ns & \\
\hline lizing problems & & ns & & & ns & & & ns & & 1.56 & .98 & 2.48 \\
\hline Low & 1.42 & 1.03 & 1.96 & 1.70 & 1.11 & 2.58 & & $\mathrm{~ns}$ & & 1.78 & 1.09 & 2.91 \\
\hline $\mathrm{ADI}$ & 1.50 & 1.07 & 2.10 & & ns & & 1.71 & 1.17 & 2.49 & & ns & \\
\hline Class & 0.32 & 0.21 & 0.50 & 0.21 & 0.13 & 0.34 & 0.46 & 0.28 & 0.76 & 0.31 & 0.17 & 0.56 \\
\hline Social activities & & ns & & & ns & & & ns & & 0.53 & 0.30 & 0.94 \\
\hline Nagelkerke $\mathrm{R}^{2}$ & .09 & & & .18 & & & .07 & & & .12 & & \\
\hline & & $\begin{array}{l}l l y / \mathrm{Vic} \\
n=12\end{array}$ & & & $\begin{array}{l}\text { rly on } \\
n=?\end{array}$ & & & $\begin{array}{l}\text { te on } \\
n=\end{array}$ & & & $\begin{array}{l}r s i s t \\
n=\end{array}$ & $B V$ \\
\hline & OR & $90 \%$ & & OR & $90 \%$ & & OR & $90 \%$ & & OR & $90 \%$ & \\
\hline Gen & 4.05 & 2.61 & 6.27 & 10.56 & 5.14 & 21.70 & 1.80 & 1.05 & 3.11 & All $\mathrm{m}$ & iales & \\
\hline Divorced parents & 1.83 & 1.13 & 2.96 & & ns & & 2.46 & 1.39 & 4.35 & & ns & \\
\hline Substance use & & ns & & 3.42 & 1.34 & 8.74 & & $\mathrm{~ns}$ & & 5 & 0.76 & 33.03 \\
\hline Internalizing problems & & ns & & 2.43 & 1.32 & 4.46 & & $\mathrm{~ns}$ & & & $\mathrm{~ns}$ & \\
\hline $\mathrm{ADH}$ & 2.04 & 1.31 & 3.18 & & ns & & & Ns & & 4.12 & 1.01 & 16.89 \\
\hline Sensatio & & ns & & & ns & & 1.95 & 1.07 & 3.55 & & ns & \\
\hline zation & 1.69 & 1.05 & 2.73 & 2.44 & 1.31 & 4.56 & & $\mathrm{~ns}$ & & & $\mathrm{~ns}$ & \\
\hline Low & 1.95 & 1.24 & 3.07 & 3.14 & 1.68 & 5.84 & & $\mathrm{~ns}$ & & 8.99 & 2 & 40.63 \\
\hline Corporal punishment & 2.61 & 1.24 & 5.48 & 4.60 & 1.87 & 11.30 & & ns & & & ns & \\
\hline Parental monitoring & & ns & & & ns & & 0.54 & 0.30 & 0.98 & & Ns & \\
\hline Likir & & ns & & & ns & & & ns & & 0.10 & 0.02 & 0.42 \\
\hline Classmates bondinging & 0.26 & 0.15 & 0.45 & 0.16 & 0.08 & 0.31 & & ns & & 0.15 & 0.03 & 0.67 \\
\hline Social activities & & ns & & 0.49 & 0.26 & 0.93 & & ns & & & ns & \\
\hline Nagelkerke $\mathrm{R}^{2}$ & .33 & & & .50 & & & .12 & & & .67 & & \\
\hline
\end{tabular}

Note: Bullying roles were compared to uninvolved students $(n=263)$, $n s=$ non-significant

Logistic regression analyses of interaction terms between each pair of significant predictors, entering each effect and the interaction term, showed seven significant interactions (see figure 1). Truancy was a risk factor for bullying perpetration mostly in girls $(\mathrm{B}=2.60, \mathrm{p}=.03)$, whereas low self-control was a risk factor for perpetration especially in boys $(\mathrm{B}=0.98, \mathrm{p}=.01)$. Truant children with high classmate bonding were at high risk of bullying perpetration $(\mathrm{B}=2.35, \mathrm{p}=.02)$. Low parental monitoring was a risk factor for perpetration more in children who did not like school than for children who did like school $(\mathrm{B}=.92, \mathrm{p}=.047)$. For children who were not truant, high classmate bonding was a protective factor against victimization $(B=2.06, p=.04)$. High classmate bonding was a protective factor against being a bully/victim for children with high 
sensation seeking $(\mathrm{B}=1.68, \mathrm{p}=.01)$. Low social activities with peers was a risk factor for victimization in boys $(\mathrm{B}=0.99, \mathrm{p}=.01)$, and substance use was a risk factor for victimization especially in children with low self-control $(\mathrm{B}=1.87, \mathrm{p}=.03)$.

(a)

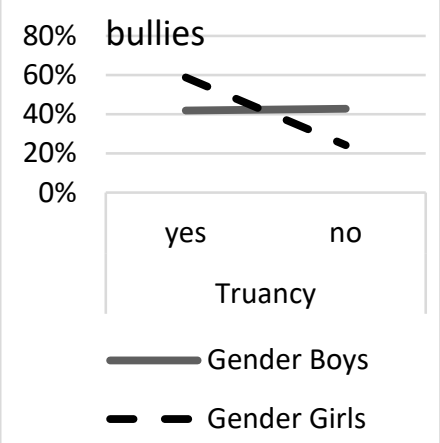

(e)

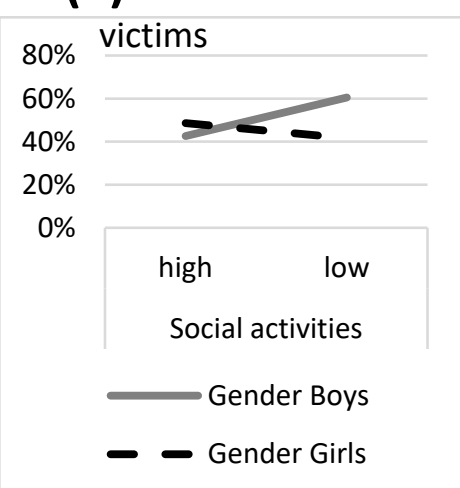

(b)

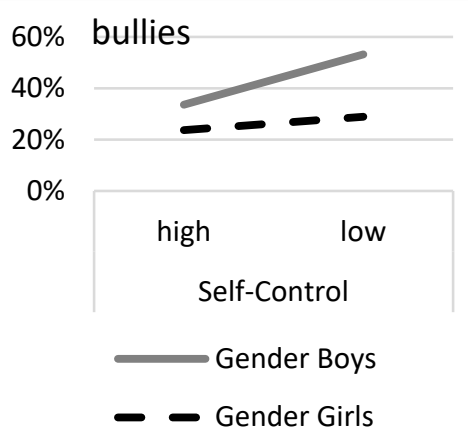

(f)

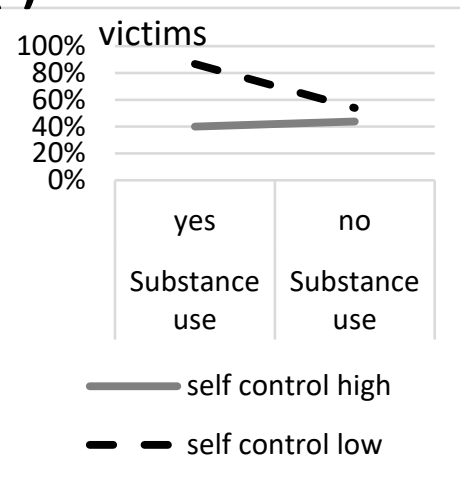

(c)

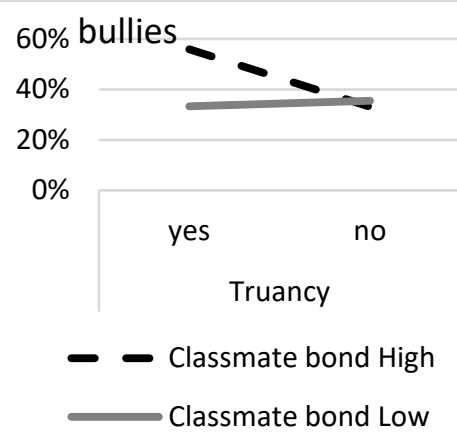

(g)

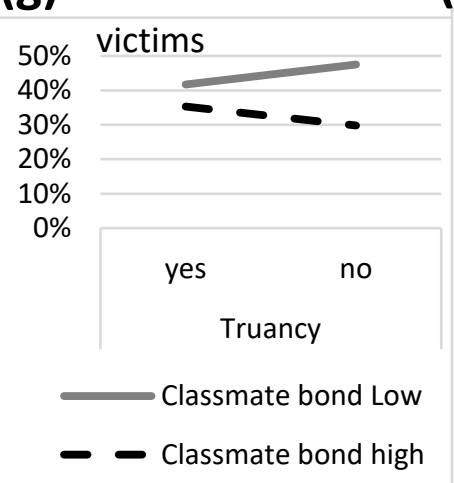

(d)

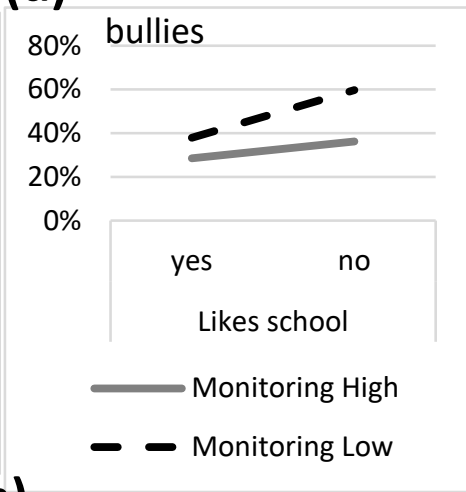

(h)

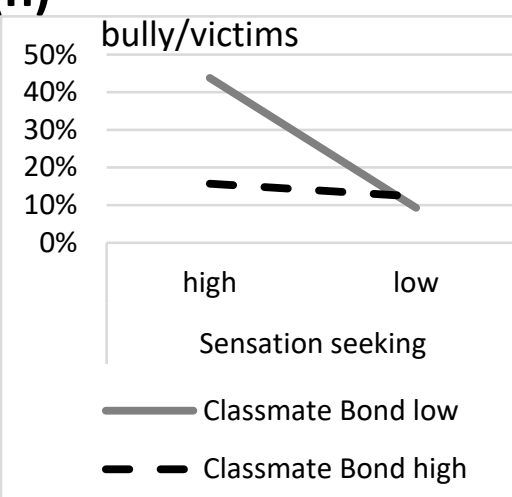

(a) $\mathrm{B}=2.60, \mathrm{SE}=1.17, p=.03$; (b) $\mathrm{B}=0.98, \mathrm{SE}=.36, p=.01$; (c) $\mathrm{B}=2.35, \mathrm{SE}=1.02, p=$ .02 ; (d) $\mathrm{B}=.92, \mathrm{SE}=.47, p=.047$; (e) $\mathrm{B}=0.99, \mathrm{SE}=0.38, \mathrm{p}=.01$ (f) $\mathrm{B}=1.87, \mathrm{SE}=0.86, \mathrm{p}=$ $.03,(\mathrm{~g}) \mathrm{B}=2.06, \mathrm{SE}=1.01, \mathrm{p}=.04,(\mathrm{~h}) \mathrm{B}=1.68, \mathrm{SE}=0.65, \mathrm{p}=.01$

Figure 1. Significant interactions between risk and protective factors for different bullying roles

\section{Discussion}

Bullying is an aggressive behavior present in children and adolescents that has some very serious consequences. Teachers and schools make an effort to decrease bullying through anti-bullying programs (Farrington \& Ttofi, 2009). Also, physicians have an important role in identifying children at risk, counseling families, screening for comorbid disorders, and advocating for prevention of bullying (Lyznicki, McCaffree, \& Robinowitz, 2004). Bullying is a challenge in primary care (Klein, Myhre, \& Ahrendt, 2013) and was found to be among the top ten health concerns of parents of children ages 2 to 17 (Shetgiri, Espelage, \& Carroll, 2015). Thus, bullying is a very serious public health 
problem that needs to be addressed by schools, by different health care services, and the society in general.

Understanding, preventing, and intervening in bullying requires knowledge about risk and protective factors. Although the number of studies on bullying have increased greatly in the past decades, comprehensive longitudinal research with several waves of data is very rare. The present study is based on seven waves of data on 916 children followed up from ages 7 to 17. Several risk and protective factors were discovered, together with interaction effects that showed how protective factors can neutralize risk factors.

The present findings showed that some mental health problems increased the risk of involvement in bullying. Internalizing problems were a risk factor for persistent victimization, and for early onset bully/victims. ADHD was a risk factor for late onset bullies, and persistent bully/victims. Thus, early detection and treatment of these mental health problems could potentially decrease bullying.

Individual factors, such as high moral neutralization and low self-control increased the risk of involvement in different bullying roles. Low self-control predicted an early onset of victimization, perpetration and being a bully/victim, and it was a risk factor for perpetration for boys more than for girls, and a risk factor for victimization, especially for children who reported substance use. Thus, it could be desirable to address these risk and protective factors in anti-bullying programs that are conducted in schools around the world (Gaffney, Ttofi, \& Farrington, 2018), preferably already in childhood. These factors are often included in social and emotional learning programs (Durlak, Weissberg, Dymnicki, Taylor, \& Schellinger, 2011), and therefore it would be desirable to increase funding for research and practice focused on social and emotional learning and anti-bullying programs, so that they could be empirically validated and conducted in all schools.

Parental monitoring was found to be a protective factor against perpetration (early onset and persistent), whereas corporal punishment was a risk factor for late onset perpetration and being an early onset bully/victim. Having divorced parents was also a risk factor for being a late onset bully/victim. For perpetration, high parental monitoring was especially protective for children who did not like school. These findings could be useful to improve parenting practice (Baldry \& Farrington, 2000; Gomez-Ortiz, Del Rey, Casas, \& Ortega-Ruiz, 2014), by recommending good parental monitoring and decreasing corporal punishment.

Classmates bonding was found to be protective against involvement in different bullying roles including early onset perpetration, any pattern of victimization, early onset and persistent bully/victims. Social activities with peers were protective against victimization, especially for boys. Thus, it is desirable to foster social competencies and social bondings, as also suggested by previous studies (Gómez-Ortiz, Romera, \& Ortega Ruiz, 2017; Ortega, Del Rey, \& Mora-Merchan, 2004). In bully/victims, there was a significant interaction effect that showed that high bonding to classmates was especially 
protective in children with high sensation seeking. Truancy was a risk factor for perpetration for girls. The relation between truancy and bonding to classmates was especially interesting. High bonding to classmates in truant children was a risk factor for perpetration, possibly because antisocial children might show a high bonding to antisocial classmates. High bonding to classmates was protective against victimization in non-truant children. These findings suggest targeting truancy and bonding to classmates within a comprehensive approach.

To our knowledge, this is the first study that included a great variety of early predictors of adolescent bullying, measured in childhood. Nevertheless, this study also has some limitations. Our analyses make it possible to discover predictors, but they do not allow establishing causal relations that could be studied in future if within-individual changes in these predictors are compared with within-individual changes in bullying. Randomized controlled trials focused on decreasing some risk factors and promoting some protective factors could shed some light on causes of bullying. Also, the current results were obtained with self-reports that can include some response bias such as social desirability, so other-reports could also be useful to confirm the results. Thus, this research fills some gaps in knowledge and also opens up new horizons for future studies.

There are several early risk and protective factors that can be addressed in children to protect them from being involved in bullying in adolescence. Knowledge about these factors and interactions among them can be very useful for public health and school policy and practice. It can be used especially by teachers, primary care and mental health professionals who can help to address mental health problems, individual factors, parenting practices, peer relationships and school factors discovered in this study.

\section{Conflict of interest}

On behalf of all authors, the corresponding author states that there is no conflict of interest.

\section{References}

Alsaker, F. D., Nägele, C., Valkanover, S., \& Hauser, D. (2008). Pathways to victimization and a multisetting intervention: Project documentation.

Antoniadou, N., Kokkinos, C. M., \& Markos, A. (2016). Possible common correlates between bullying and cyber-bullying among adolescents. Psicología Educativa, 22, 27-38.

Averdijk, M., Müller, B., Eisner, M. P., \& Ribeaud, D. (2011). Bullying victimization and later anxiety and depression among pre-adolescents in Switzerland. Journal of Aggression, Conflict and Peace Research, 2, 103-109.

Bacchini, D., Affuso, G., \& Trotta, T. (2008). Temperament, ADHD and peer relations among schoolchildren: The mediating role of school bullying. Aggressive Behavior, 34(5), 447-459. 
Baldry, A. C., \& Farrington, D. P. (2000). Bullies and Delinquents: Personal Characteristics and Parental Styles. Journal of Community \& Applied Social Psychology, 10, 17-31.

Benedini, K. M., Fagan, A. A., \& Gibson, C. L. (2016). The cycle of victimization: The relationship between childhood maltreatment and adolescent peer victimization. Child Abuse \& Neglect, 59, 111-121.

Bowes, L., Maughan, B., Ball, H., Shakoor, S., Ouellet-Morin, I., Caspi, A., et al. (2013). Chronic bullying victimization across school transitions: The role of genetic and environmental influences. Development and Psychopathology, 25(2), 333-346.

Brendgen, M., Girard, A., Vitaro, F., Dionne, G., \& Boivin, M. (2016). Personal and Familial Predictors of Peer Victimization Trajectories From Primary to Secondary School. Developmental Psychology, 52(7), 1103-1114.

Collins, L. M., \& Lanza, S. T. (2010). Latent Class and Latent Transition Analysis. New Jersey: Wiley.

Cook, C. R., Williams, K. R., Guerra, N. G., Kim, T. E., \& Sadek, S. (2010). Predictors of Bullying and Victimization in Childhood and Adolescence: A Meta-analytic Investigation. School Psychology Quarterly, 25(2), 65-83.

Copeland, W. E., Wolke, D., Angold, A., \& Costello, E. J. (2013). Adult Psychiatric Outcomes of Bullying and Being Bullied by Peers in Childhood and Adolescence. Jama Psychiatry, 70(4), 419-426.

Cross, D., Lester, L., \& Barnes, A. (2015). A longitudinal study of the social and emotional predictors and consequences of cyber and traditional bullying victimisation. International Journal of Public Health, 60(2), 207-217.

Del Rey, R., Casas, J. A., \& Ruiz, R. O. (2017). The Development and Validation of the Schoolwide Climate Scale. Universitas Psychologica, 16(1).

Durlak, J. A., Weissberg, R. P., Dymnicki, A. B., Taylor, R. D., \& Schellinger, K. B. (2011). The Impact of Enhancing Students' Social and Emotional Learning: A Meta-Analysis of School-Based Universal Interventions. Child Development, 82(1), 405-432.

Dussich, J. P. J., \& Maekoya, C. (2007). Physical child harm and bullying-related behaviors - A comparative study in Japan, south Africa, and the United States. International Journal of Offender Therapy and Comparative Criminology, 51(5), 495-509.

Eisner, M. P., \& Malti, T. (2015). Aggressive and violent behavior. In M. E. Lamb (vol. ed.) \& R. M. Lerner (Series ed.) (Eds.), Handbook of child psychology and developmental science, Vol. 3: Social, emotional and personality development (pp. 795-884). New York, NY: Wiley.

Espelage, D. L. (2014). Ecological Theory: Preventing Youth Bullying, Aggression, and Victimization. Theory into Practice, 53(4), 257-264.

Espelage, D. L., Rao, M. A., \& De la Rue, L. (2013). Current research on school-based bullying: A social-ecological perspective. Journal of Social Distress and the Homeless, 22(1), 7-21. 
Fanti, K. A., \& Kimonis, E. R. (2013). Dimensions of Juvenile Psychopathy Distinguish "Bullies," "Bully-Victims," and "Victims". Psychology of Violence, 3(4), 396409.

Farrington, D. P., \& Ttofi, M. M. (2009). School-based programs to reduce bullying and victimization. Campbell Systematic Reviews, 6.

Farrington, D. P., Ttofi, M. M., Crago, R. V., \& Coid, J. W. (2015). Intergenerational similarities in risk factors for offending. Journal of Developmental and LifeCourse Criminology, 1, 48-62.

Gaffney, H., Ttofi, M. M., \& Farrington, D. P. (2018). Evaluating the effectiveness of school-bullying prevention programs: An updated meta-analytical review. Aggression and Violent Behavior., Online First.

Gastic, B. (2008). School truancy and the disciplinary problems of bullying victims. Educational Review, 60(4), 391-404.

Gini, G., \& Pozzoli, T. (2013). Bullied Children and Psychosomatic Problems: A Metaanalysis. Pediatrics, 132(4), 720-729.

Gini, G., Pozzoli, T., \& Hymel, S. (2014). Moral disengagement among children and youth: A meta-analytic review of links to aggressive behavior. [Article]. Aggressive Behavior, 40(1), 56-68.

Gini, G., Pozzoli, T., Lenzi, M., \& Vieno, A. (2014). Bullying Victimization at School and Headache: A Meta-Analysis of Observational Studies. Headache, 54(6), 976986.

Gomez-Ortiz, O., Del Rey, R., Casas, J. A., \& Ortega-Ruiz, R. (2014). Parenting styles and bullying involvement. Cultura Y Educacion, 26(1), 132-158.

Gomez-Ortiz, O., Romera, E. M., Ortega-Ruiz, R., Herrera, M., \& Norman, J. O. (2019). Multidimensional Social Competence in Research on Bullying Involvement: A Cross-Cultural Study. Behavioral Psychology-Psicologia Conductual, 27(2), 217238.

Gómez-Ortiz, O., Romera, E. M., \& Ortega Ruiz, R. (2017). Multidimensionality of Social Competence: Measurement of the Construct and its Relationship with Bullying Roles. Revista de Psicodidáctica, 22.

Grasmick, H. G., Tittle, C. R., Bursik, R. J., \& Arneklev, B. J. (1993). Testing the Core Empirical Implications of Gottfredson and Hirschi General-Theory of Crime. Journal of Research in Crime and Delinquency, 30(1), 5-29.

Hemphill, S. A., Kotevski, A., Tollit, M., Smith, R., Herrenkohl, T. I., Toumbourou, J. W., et al. (2012). Longitudinal Predictors of Cyber and Traditional Bullying Perpetration in Australian Secondary School Students. Journal of Adolescent Health, 51(1), 59-65.

Holt, M. K., Vivolo-Kantor, A. M., Polanin, J. R., Holland, K. M., DeGue, S., Matjasko, J. L., et al. (2015). Bullying and Suicidal Ideation and Behaviors: A MetaAnalysis. Pediatrics, 135(2), E496-E509.

Kim, Y. S., Boyce, W. T., Koh, Y. J., \& Leventhal, B. L. (2009). Time Trends, Trajectories, and Demographic Predictors of Bullying: A Prospective Study in Korean Adolescents. Journal of Adolescent Health, 45(4), 360-367. 
Klein, D. A., Myhre, K. K., \& Ahrendt, D. M. (2013). Bullying Among Adolescents: A Challenge in Primary Care. American Family Physician, 88(2), 87-+.

Lereya, S. T., Samara, M., \& Wolke, D. (2013). Parenting behavior and the risk of becoming a victim and a bully/victim: A meta-analysis study. Child Abuse \& Neglect, 37(12), 1091-1108.

Lyznicki, J. M., McCaffree, M. A., \& Robinowitz, C. B. (2004). Childhood bullying: Implications for physicians. American Family Physician, 70(9), 1723-1728.

Ortega, R., Del Rey, R., \& Mora-Merchan, J. A. (2004). SAVE Model: An antibullying intervention in Spain. In P. K. Smith, D. Pepler \& K. Rigby (Eds.), Bullying in schools: How successful can interventions be? (pp. 167-186). Cambridge, UK: Cambridge University Press.

Pouwels, J. L., Salmivalli, C., Saarento, S., van den Berg, Y. H., Lansu, T. A., \& Cillessen, A. H. (2017). Predicting Adolescents' Bullying Participation from Developmental Trajectories of Social Status and Behavior. Child Development.

Reijntjes, A., Kamphuis, J. H., Prinzie, P., Boelen, P. A., van der Schoot, M., \& Telch, M. J. (2011). Prospective Linkages Between Peer Victimization and Externalizing Problems in Children: A Meta-Analysis. Aggressive Behavior, 37(3), 215-222.

Reijntjes, A., Kamphuis, J. H., Prinzie, P., \& Telch, M. J. (2010). Peer victimization and internalizing problems in children: A meta-analysis of longitudinal studies. Child Abuse \& Neglect, 34(4), 244-252.

Ribeaud, D., \& Eisner, M. (2010a). Are Moral Disengagement, Neutralization Techniques, and Self-Serving Cognitive Distortions the Same? Developing a Unified Scale of Moral Neutralization of Aggression. International Journal of Conflict and Violence, 4(2), 298-315.

Ribeaud, D., \& Eisner, M. (2010b). Risk factors for aggression in pre-adolescence: Risk domains, cumulative risk and gender differences - Results from a prospective longitudinal study in a multi-ethnic urban sample. European Journal of Criminology, 7(6), 460-498.

Romera, E. M., Casas, J. A., Gomez-Ortiz, O., \& Ortega-Ruiz, R. (2019). Moral domain as a risk and protective factor against bullying. An integrating perspective review on the complexity of morality. Aggression and Violent Behavior, 45, 75-82.

Schafer, M., Korn, S., Brodbeck, F. C., Wolke, D., \& Schulz, H. (2005). Bullying roles in changing contexts: The stability of victim and bully roles from primary to secondary school. International Journal of Behavioral Development, 29(4), 323335.

Shelton, K. K., Frick, P. J., \& Wootton, J. (1996). Assessment of parenting practices in families of elementary school-age children. Journal of Clinical Child Psychology, 25(3), 317-329.

Shetgiri, R., Espelage, D. L., \& Carroll, L. (2015). Practical Strategies for Clinical Management of Bullying. New York: Springer.

Smith, P. K., \& Brain, P. (2000). Bullying in schools: Lessons from two decades of research. Aggressive Behavior, 26(1), 1-9.

Solberg, M. E., \& Olweus, D. (2003). Prevalence estimation of school bullying with the Olweus Bully Victim Questionnaire. Aggressive Behavior, 29(3), 239-268. 
Sourander, A., Gyllenberg, D., Klomek, A. B., Sillanmaki, L., Ilola, A. M., \& Kumpulainen, K. (2016). Association of Bullying Behavior at 8 Years of Age and Use of Specialized Services for Psychiatric Disorders by 29 Years of Age. Jama Psychiatry, 73(2), 159-165.

Sourander, A., Helstela, L., Helenius, H., \& Piha, J. (2000). Persistence of bullying from childhood to adolescence - A longitudinal 8-year follow-up study. Child Abuse \& Neglect, 24(7), 873-881.

Swearer, S. M., \& Cary, P. T. (2003). Perceptions and attitudes toward bullying in middle school youth: A developmental examination across the bully/victim continuum. . Journal of Applied School Psychology, 19, 63-79.

Tremblay, R. E., Loeber, R., Gagnon, C., Charlebois, P., Larivee, S., \& Leblanc, M. (1991). Disruptive Boys with Stable and Unstable High Fighting Behavior Patterns during Junior Elementary-School. Journal of Abnormal Child Psychology, 19(3), 285-300.

Ttofi, M. M., Farrington, D. P., Losel, F., Crago, R. V., \& Theodorakis, N. (2016). School Bullying and Drug Use Later in Life: A Meta-Analytic Investigation. School Psychology Quarterly, 31(1), 8-27.

Ttofi, M. M., Farrington, D. P., Losel, F., \& Loeber, R. (2011). The predictive efficiency of school bullying versus later offending: A systematic/meta-analytic review of longitudinal studies. Criminal Behaviour and Mental Health, 21(2), 80-89.

Ttofi, M. M., Farrington, D. P., Lösel, F., \& Loeber, R. (2011). Do the victims of school bullies tend to become depressed later in life? A systematic review and metaanalysis of longitudinal studies. Journal of Aggression, Conflict and Peace Research, 3, $63-73$.

Unnever, J. D., \& Cornell, D. G. (2003). Bullying, self-control, and ADHD. Journal of Interpersonal Violence, 18(2), 129-147.

Valdebenito, S., Ttofi, M., \& Eisner, M. (2015). Prevalence rates of drug use among school bullies and victims: A systematic review and meta-analysis of crosssectional studies. Aggression and Violent Behavior, 23, 137-146.

Valdebenito, S., Ttofi, M. M., Eisner, M. P., \& Gaffney, H. (2017). Weapon carrying in and out of school among pure bullies, pure victims and bully-victims: a systematic review and meta-analysis of cross-sectional and longitudinal studies. Aggression and Violent Behavior, 33, 62-77.

Young, S., Moss, D., Sedgwick, O., Fridman, M., \& Hodgkins, P. (2015). A meta-analysis of the prevalence of attention deficit hyperactivity disorder in incarcerated populations. Psychological Medicine, 45(2), 247-258.

Zych, I., Farrington, D. P., \& Ttofi, M. M. (2019). Protective factors against bullying and cyberbullying: A systematic review of meta-analyses. Aggression and Violent Behavior, 45, 4-19.

Zych, I., Ortega-Ruiz, R., \& Del Rey, R. (2015). Systematic review of theoretical studies on bullying and cyberbullying: Facts, knowledge, prevention, and intervention. Aggression and Violent Behavior, 23, 1-21. 
Zych, I., Ttofi, M. M., Farrington, D. P., Ribeaud, D., \& Eisner, M. P. (2020). A longitudinal study on stability and transitions among bullying roles. Child Development, 91, 527-545. 